\title{
Efficiency Evaluation for Smart Grid Management Based on Stochastic Frontier Model and Data Envelope Analyses Model
}

\author{
Yu Xiaobao, Tan Zhongfu, Chen Kangting, Ju Liwei, and He Puyu \\ North China Electric Power University, Beijing 102206, China \\ Correspondence should be addressed to Yu Xiaobao; yuxiaobao1222@163.com
}

Received 29 July 2015; Accepted 28 September 2015

Academic Editor: Mohamed Djemai

Copyright ( 2015 Yu Xiaobao et al. This is an open access article distributed under the Creative Commons Attribution License, which permits unrestricted use, distribution, and reproduction in any medium, provided the original work is properly cited.

\begin{abstract}
For the technical and allocative efficiency evaluation of smart grid, this paper has proposed two methods. One is based on Data Envelopment Analysis and another is based on Stochastic Frontier Model. Among them, the former considered the dynamics of smart grid development and development dynamics is the influence parameter. The latter analyzed self-duality between the Cobb-Douglas production function and cost function; then, it deduced the smart grid resources optimization allocative efficiency evaluation model which can avoid price information needs of input factor in conventional allocative efficiency evaluation. The validity and rationality of the two methods are verified by a case study.
\end{abstract}

\section{Introduction}

In process of its construction, the advanced technology is the key factor for the development of the grid in the intelligent direction [1]. The impact of the assessment technology is significant for the smart grid. From the point of technological progress and technical efficiency, analysis of this effect is the main research idea at home and abroad [2]. In economic management science, the technical efficiency is the ability of maximum output under the fixed input factors of the production unit [3]. Technological progress indicates the contribution of technology to economic growth and is reflected as the effect of production units.

In network analysis of technical progress, people have proposed the intelligent technique evaluation method with Cobb-Douglas production function which reflects the level of intelligent power grid development through contribution degree of computing technology to economic benefits [4]. Data Envelopment Analysis (DEA) has been used to evaluate the technical efficiency and scale efficiency of the power network [5]. Some scholars also use DEA to evaluate the technical efficiency of the hydroelectric power enterprise or transmission and distribution system $[6,7]$.
One of the overall planning objectives for smart grid is to achieve a large range of resource optimization allocation [8]. As an important platform for optimizing the energy resources, the smart grid resource that optimizes allocation ability can be evaluated by allocative efficiency, which can also reflect the construction effect of optimizing asset. Allocative efficiency refers to the ability to rationally configure various factors of production when the input elements' price information and technical level are fixed. However, in studies of evaluating the allocative efficiency, most scholars take the cost function as the theoretical basis and take the price information of the input elements as the precondition, which restricts the effective evaluation for allocative efficiency [9$11]$.

Although the smart grid is in the phase of overall construction, the price information of input element is often difficult to get in assessment of technical efficiency. Therefore, according to the analysis of self-dual characteristic between the Cobb-Douglas production function and cost function, this paper has proposed the smart grid efficiency evaluation method based on Data Envelopment Analysis and Stochastic Frontier Model, then compared the two models and verified their usefulness according to the calculation results. 


\section{Efficiency Assessment Model}

2.1. Data Envelopment Evaluation Model. Data envelopment evaluation model is performed to evaluate the efficiency [12]. This model considers the development of smart grid in time continuity through its improvement. That is, the construction effect of smart grid at the end of the last time should be the initial condition of the next time, so the model of management efficiency assessment is dynamic. At the same time, it takes into account the relationships between different attributes, that is; the benefit of building an attribute can be construction investment of another attribute. The objective function of the data envelopment evaluation model is as follows:

$$
\min \frac{\sum_{t=1}^{T} W^{t}\left(\sum_{k=1}^{K} \omega^{k}\left(1-\left(1 / m_{k}\right) \sum_{i=1}^{m_{k}}\left(s_{i o k}^{t-} / x_{i o k}^{t}\right)\right)\right)}{\sum_{t=1}^{T} W^{t}\left(\sum_{k=1}^{K} \omega^{k}\left(1+\left(1 / r_{k}\right) \sum_{i=1}^{r_{k}}\left(s_{r o k}^{t+} / y_{r o k}^{t}\right)\right)\right)} .
$$

In this formula, $x_{i j k}^{t}$ is the value of input indicator $i$ under the attribute $k$ of decision element $j$ in $t$ years; $y_{r j k}^{t}$ is the value of output indicator $i$ under the attribute $k$ of decision element $j$ in $t$ years; $s_{i j k}^{t-}$ is the slack variable of input indicator $i$ under the attribute $k$ of decision element $j$ in $t$ years; $s_{r j k}^{t+}$ is the slack variable of output indicator $i$ under the attribute $k$ of decision element $j$ in $t$ years.

The constraints are shown below:

$$
\text { s.t. }\left\{\begin{array}{l}
\sum_{j=1}^{n} \lambda_{j k}^{t} x_{i j k}^{t}+s_{i k}^{t-}=x_{i o k}^{t}, \quad o=1, \ldots, n ; k=1, \ldots, K ; i=1, \ldots, m ; t=1, \ldots, T \\
\sum_{j=1}^{n} \lambda_{j k}^{t} y_{r j k}^{t}-s_{r k}^{t-}=y_{r o k}^{t}, \quad o=1, \ldots, n ; k=1, \ldots, K ; r=1, \ldots, s ; t=1, \ldots, T \\
\lambda_{j k}^{t} z_{j k_{i}}^{t, t+1}=\sum_{j=1}^{n} \lambda_{j k}^{t+1} z_{j k_{i}}^{t, t+1} \\
\sum_{j=1}^{n} \lambda_{j k}^{t} z_{j(k, h)_{i}}^{t}=\sum_{j=1}^{n} \lambda_{j h}^{t+1} z_{j(k, h)}^{t} \\
\sum_{j=1}^{n} \lambda_{j}^{k}=1, \quad k=1, \ldots, K \\
\lambda_{j k}^{t} \geq 0, s_{i}^{k-} \geq 0, s_{r}^{k+} \geq 0, \quad i=1, \ldots, m ; r=1, \ldots, s ; k=1, \ldots, K .
\end{array}\right.
$$

In this formula, $z_{j(k, h)_{i}}^{t}$ is correlation value of decision element $j$ from the attribute $k$ to attribute $h$ in $t$ time slot. $z_{j k_{i}}^{t, t+1}$ is influence value of decision element $j$ in attribute $k$ from $t$ years to $t+1$ years.

Through the optimization of the model, the parameters are set as follows:

$$
\begin{aligned}
& \sum_{j=1}^{n} \lambda_{j k}^{t} z_{j(k, h)_{i}}^{t}=z_{o(k, h)_{i}}^{t} \\
& \sum_{j=1}^{n} \lambda_{j h}^{t} z_{j(k, h)_{i}}^{t}=z_{o(k, h)_{i}}^{t} .
\end{aligned}
$$

From this, the efficiency of each decision element can be calculated as follows:

$$
\theta_{o}^{t}=\frac{\sum_{k=1}^{K} \omega^{k}\left(1-\left(1 / m_{k}\right) \sum_{i=1}^{m_{k}}\left(s_{i o k}^{t-} / x_{i o k}^{t}\right)\right)}{\sum_{k=1}^{K} \omega^{k}\left(1+\left(1 / r_{k}\right) \sum_{i=1}^{r_{k}}\left(s_{r o k}^{t+} / y_{r o k}^{t}\right)\right)} .
$$

Among them, the attribute efficiency values of decisionmaking unit DMU are as follows:

$$
\theta_{o k}=\frac{\sum_{t=1}^{T} W^{t}\left(1-\left(1 / m_{k}\right) \sum_{i=1}^{m_{k}}\left(s_{i o k}^{t-} / x_{i o k}^{t}\right)\right)}{\sum_{t=1}^{T} W^{t}\left(1+\left(1 / r_{k}\right) \sum_{i=1}^{r_{k}}\left(s_{\text {rok }}^{t+} / y_{\text {rok }}^{t}\right)\right)} .
$$

2.2. Stochastic Frontier Analysis Model. In quantitative assessment of technological progress, the speed of technological progress and the contribution of technology can measure the technological development level of smart grid [13]. However, this evaluation method can only carry on the appraisal to the single grid enterprises in different time sections of smart grid technology development status. The evaluation results can only reflect their own intelligence level change with time, so it cannot cope with the horizontal comparison of a plurality of grid enterprises. In the evaluation of building smart grid technology in different power companies, the use of technical efficiency indicators can meet the requirement. The relationship between technological progress and technical efficiency can be reflected by Figure 1 .

The technology efficiency is a relative concept, which can be understood as the ratio of the actual return output and the maximum output of the smart grid in the case of the given input elements [14]. In Figure 1, the curve OR represents the output front or the maximum output. When the benefits of the smart grid are at the point of $\mathrm{B}$, which is relative to the $\mathrm{C}$ points on the front face, the smart grid technology efficiency is defined as $\mathrm{AB} / \mathrm{AC}$. When technology advances, the $\mathrm{OR}$ becomes $\mathrm{OR}^{\prime}$. If earning remains $B$ point, the technical efficiency will be reduced to $A B /$ AD. 


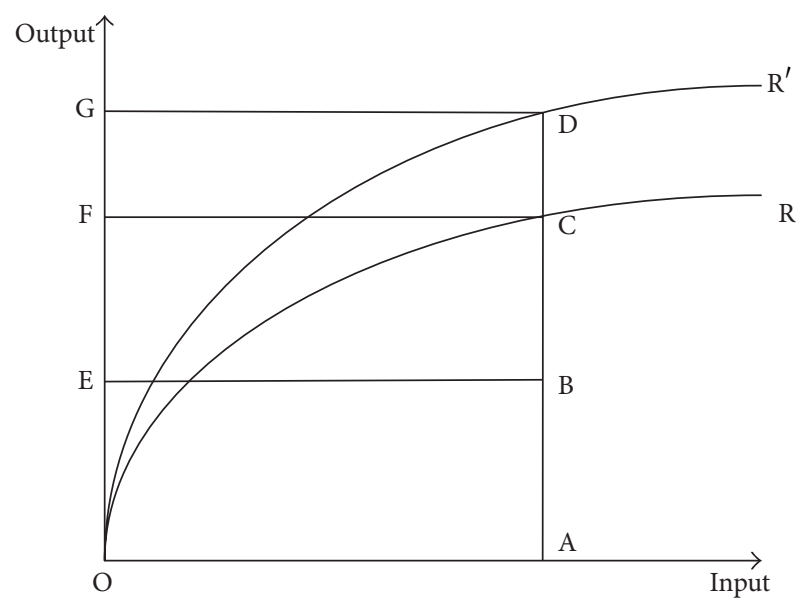

FIGURE 1: The sketch map of the relationship between technical efficiency and technical progress.

Logarithmic form of Cobb-Douglas production function used in this paper is as follows:

$$
\begin{aligned}
\ln y_{i t} & =A_{0}+\alpha_{i t} \ln k_{i t}+\beta_{i t} \ln l_{i t}+v_{i t}-u_{i t} \\
v_{i t} & \sim N\left(0, \sigma_{v}^{2}\right) \\
u_{i t} & \sim N^{+}\left(\mu_{i t}, \sigma_{i t}^{2}\right) .
\end{aligned}
$$

In these formulas, $y_{i t}$ is actual output of power grid enterprise $i$ in period $T . k_{i t}$ and $l_{i t}$ are input quantity and labor number of power grid enterprise $i$ in period $T . v_{i t}$ is the random error of power grid enterprise $i$ in period $T . u_{i t}$ refers to technology rather than efficiency. $\alpha_{i t}$ and $\beta_{i t}$ are elasticity coefficients.

The technical efficiency of grid enterprise $i$ is defined as

$$
r_{i t}=\frac{y_{i t}}{\overline{y_{i t}}}=e^{-u_{i t}}
$$

Among them, $\overline{y_{i t}}$ refers to the largest output of the stochastic frontier of grid enterprise $i$. The function form is

$$
\overline{y_{i t}}=A k_{i t}^{\alpha_{i t}} l_{i t}^{\beta_{i t}} \exp \left(-v_{i t}\right) \text {. }
$$

Formula (7) is technical efficiency function based on the Stochastic Frontier Model. Compared with technical efficiency solution model established by DEA, the technical efficiency calculation method in this paper is only related to $u_{i t} \cdot u_{i t}$ is satisfied with nonnegative truncated normal distribution, which can be obtained by statistical analysis of sample data. To obtain technical efficiency need establish DEA optimization model. Although it is not necessary to analyze the sample data, the solving process is often restricted by the dimension. The bigger the solution, the smaller the chance to obtain the feasible solution.

Improving the utilization of assets and the operating efficiency is the main characteristic of smart grid. At the same time, high efficiency is the core value of the smart grid for research institutions and power companies at home and abroad. From the point of scientific research, the allocative efficiency of quantitative evaluation for smart grid can not only reflect the grid optimization allocation of resources but also reflect the benefits of efficiency.

Combining production function and cost function is one of the theoretical tools to realize allocative efficiency evaluation. The Cobb-Douglas cost function [15], which has the stochastic frontier characteristic, can be defined as

$$
\ln \left(C_{i t}\right)=\sum_{s=1}^{n}\left[\ln \left(\omega_{i t}^{s}\right)+\ln \left(X_{i t}^{s}\right)+v_{i t}\right] .
$$

In this formula, $C_{i t}$ is the total cost of power company $i$ in $t$ period. $\omega_{i t}^{s}$ is the price of input element $s$ of power company $i$ in $t$ period. $X_{i t}^{s}$ is the input element $s$ of power company $i$ in $t$ period, and it only takes $k_{i t}$ or $l_{i t}$. $S$ expresses input element category.

From formula (9), it can be seen that if the application cost function can be used to evaluate the intelligent power grid, price information of input elements is the primary condition. For the power grid enterprise, the investment in the smart grid and equipment device belong to the management of financial, organization, and other departments. Taking into account the complexity or other questions, accessing price information is not easy. Therefore, it is necessary to explore a new method to accurately evaluate the efficiency of the smart grid resource and energy optimization allocation.

In order to avoid the requirement for the input factor price, according to the inherent duality between production function and cost function, the optimization model can be established with formula (9):

$$
\begin{array}{ll}
\min & C_{i t} \\
\text { s.t. } & y_{i t}=f\left(X_{i t}, t\right) .
\end{array}
$$

The objective function in the type (10) is the minimum cost. Constraint conditions indicate production conditions that should satisfy Cobb-Douglas production function. The conditional extreme problem can be solved by the following process:

$$
F_{i t}\left(X_{i t}, t\right)=C_{i t}+\lambda f\left(X_{i t}, t\right)
$$

The optimal solution satisfies the following conditions:

$$
\frac{\partial F_{i t}}{\partial X_{i t}}=\frac{\partial C_{i t}}{\partial X_{i t}}+\lambda \frac{\partial f\left(X_{i t}, t\right)}{\partial X_{i t}}=0
$$

In Cobb-Douglas production function, investment elements are investment cost and labor force. It can be obtained by (12):

$$
\begin{aligned}
& \omega_{i t}^{k}=\lambda A \alpha k_{i t}^{\alpha-1} l_{i t}^{\beta} \exp \left(-u_{i t}\right) \\
& \omega_{i t}^{l}=\lambda A \beta k_{i t}^{\alpha} l_{i t}^{\beta-1} \exp \left(-u_{i t}\right) .
\end{aligned}
$$

Among them, production function is the index of (1) on both sides:

$$
y_{i t}=A k_{i t}^{\alpha_{i t}} l_{i t}^{\beta_{i t}} \exp \left(v_{i t}-u_{i t}\right)
$$


The ratio of the upper and lower equations in formula (13) is

$$
k_{i t}=\frac{\alpha_{i t}}{\beta_{i t}} \frac{\omega_{i t}^{l}}{\omega_{i t}^{k}} l_{i t} .
$$

From formulas (15) and (13), $k_{i t}$ can be eliminated. We can get

$$
\left(\omega_{i t}^{l} l_{i t}\right)^{\alpha_{i t}+\beta_{i t}-1}=\frac{\left(\lambda \alpha_{i t}\right)^{-1}\left(\alpha_{i t} / \beta_{i t}\right)^{1-\alpha}}{A \exp \left(-u_{i t}\right)}\left(\omega_{i t}^{k}\right)^{\alpha_{i t}}\left(\omega_{i t}^{l}\right)^{\beta_{i t}} .
$$

From formula (13), it can be got that

$$
\left(\lambda \alpha_{i t}\right)^{-1}=\frac{A k_{i t}^{\alpha_{i t}-1} l_{i t}^{\beta_{i t}}}{\omega_{i t}^{k}} \exp \left(-u_{i t}\right)=\frac{y_{i t}}{\omega_{i t}^{k} k_{i t}} \exp \left(-v_{i t}\right) .
$$

Then, from formulas (16) and (17), $\left(\lambda \alpha_{i t}\right)^{-1}$ can be eliminated. We can get

$$
\begin{aligned}
& \omega_{i t}^{l} l_{i t} \\
& =\frac{\beta_{i t}}{\alpha_{i t}}\left(\frac{\alpha_{i t}}{\beta}\right)^{\beta_{i t} /\left(\alpha_{i t}+\beta_{i t}\right)} A^{-1 /\left(\alpha_{i t}+\beta_{i t}\right)}\left(\omega_{i t}^{k}\right)^{\alpha_{i t} /\left(\alpha_{i t}+\beta_{i t}\right)} \\
& \quad \cdot\left(\omega_{i t}^{l}\right)^{\beta_{i t} /\left(\alpha_{i t}+\beta_{i t}\right)} y_{i t}^{1 /\left(\alpha_{i t}+\beta_{i t}\right)} \exp \left(\frac{u_{i t}}{\alpha_{i t}+\beta_{i t}}-v_{i t}\right) .
\end{aligned}
$$

$\omega_{i t}^{k} k_{i t}$ can be got similarly. The cost function expressed in form (15) can be written as

$$
\begin{aligned}
C_{i t} & =\left[\omega_{i t}^{k} k_{i t}+\omega_{i t}^{l} l_{i t}\right] \exp \left(v_{i t}\right)=\left(\frac{\beta_{i t}}{\alpha_{i t}}+1\right) \\
& \cdot\left(\frac{\alpha_{i t}}{\beta_{i t}}\right)^{\beta_{i t} /\left(\alpha_{i t}+\beta_{i t}\right)} A^{-1 /\left(\alpha_{i t}+\beta_{i t}\right)}\left(\omega_{i t}^{k}\right)^{\alpha_{i t} /\left(\alpha_{i t}+\beta_{i t}\right)} \\
& \cdot\left(\omega_{i t}^{l}\right)^{\beta_{i t} /\left(\alpha_{i t}+\beta_{i t}\right)} y_{i t}^{1 /\left(\alpha_{i t}+\beta_{i t}\right)} \exp \left(\frac{u_{i t}}{\alpha_{i t}+\beta_{i t}}\right) .
\end{aligned}
$$

According to the general form of the cost function in CobbDouglas type, we can see cost efficiency is the index term in cost function. Therefore, cost efficiency is

$$
r_{i t}^{c}=\exp \left(-v_{i t}\right)=\exp \left(-\frac{u_{i t}}{\alpha_{i t}+\beta_{i t}}\right) .
$$

The relationship among technical efficiency, cost efficiency, and allocative efficiency is

$$
r_{i t}^{a}=\frac{\exp \left(-v_{i t}\right)}{\exp \left(-u_{i t}\right)}=\exp \left(u_{i t}-v_{i t}\right) .
$$

Then, from formulas (20) and (21), allocative efficiency can be expressed:

$$
r_{i t}^{a}=\exp \left[-u_{i t}\left(\frac{1}{\alpha_{i t}+\beta_{i t}}+1\right)\right]
$$

From formula (22), we can see allocative efficiency $r_{i t}^{a}$ can be obtained by technical efficiency $r_{i t}$ and elastic coefficient $\alpha_{i t}$ and $\beta_{i t}$. Demands of input factor prices $\omega_{i t}^{s}$ can be avoided.

\section{Parameter Estimation}

For Cobb-Douglas production function with stochastic frontier characteristic, in the realization of technology efficiency and allocative efficiency evaluation, parameters to be estimated are elastic coefficients $\left(\alpha_{i t}\right.$ and $\left.\beta_{i t}\right)$ and random disturbance $\left(u_{i t}\right)$.

Based on the observation data of input and output in smart grid, this paper estimates the parameter through least squares which is based on minimum squared residuals [16]. Considering reliability of parameter estimation, the unbiased, minimum variance and consistency need are verified. Significance test for single parameter is generally $T$ test. $P$ is used to judge significance that is obtained by $T$ test. $P$ is the probability value. It is usually used to describe the minimum confidence level of $T$ value in the rejection of virtual hypothesis, which can be generally obtained by results of statistical software. If $P$ is small, evidence to reject virtual hypothesis is sufficient and the saliency of estimated parameters is strong.

The model test is determined by statistical theory. The purpose is to evaluate the correctness and reliability of model in the process of setting and estimating parameters [17]. For the multivariate linear regression model, significance test of regression coefficient is necessary, and it is also important to test the goodness of fit and significance of regression equation.

(1) Goodness of Fit $\left(R^{2}\right) \cdot R^{2}$ describes the percentage of input factor $X_{i t}$ to output $Y_{i t}$ in logarithmic form. $R^{2}$ is a quantitative index for sample observation and goodness of fit of regression model. The bigger $R^{2}$ is, the better the goodness of fit is. The fitting index of the total regression model in the $T$ period is

$$
\left(R^{2}\right)_{t}=\frac{\sum_{i=1}^{M}\left(\ln \widehat{y}_{i t}\right)^{2}}{\sum_{i=1}^{M} e_{i t}^{2}+\sum_{i=1}^{M}\left(\ln \widehat{y}_{i t}\right)^{2}} .
$$

In this formula, $\widehat{y}_{i t}$ is regression value of $y_{i t}$; $M$ refers to total number of species of $y_{i t} ; \sum_{i=1}^{M}\left(\ln \widehat{y}_{i t}\right)^{2}$ expresses regression sum of squares referred to RS; $\sum_{i=1}^{M} e_{i t}^{2}$ expresses residual sum of squares referred to ES, which can be obtained by least squares method.

(2) Hypothesis Testing of Related Constraints. In order to test the economic return of scale in construction of smart grid, it can use hypothesis testing of constraints to identify the applicability of production function, which is to judge the linear equality constraint: $\alpha_{i t}+\beta_{i t}=1$. The constraint can be checked by the following $F$ test method:

(1) Set assumptions: null hypothesis: $H_{0}: \alpha_{i t}+\beta_{i t}=1$ (restraint); optional hypothesis: $H_{1}: \alpha_{i t}+\beta_{i t} \neq 1$ (unrestraint).

(2) Under the condition of $H_{0}$, the statistics $F$ is

$$
F=\frac{\left(R_{u}^{2}-R_{s}^{2}\right) / m}{\left(1-R_{u}^{2}\right) /(n-k-1)} \sim F(m, n-k-1) .
$$


TABLE 1: Data collection.

\begin{tabular}{|c|c|c|c|c|c|c|c|c|c|}
\hline \multirow[b]{2}{*}{ Order } & \multirow[b]{2}{*}{ Power company } & \multicolumn{5}{|c|}{ Input amount } & \multicolumn{3}{|c|}{ Output amount } \\
\hline & & $\begin{array}{l}\text { (1) Power } \\
\text { grid } \\
\text { investment } \\
\text { (ten } \\
\text { thousand } \\
\text { yuan) }\end{array}$ & $\begin{array}{c}(2) \\
\text { Infrastructure } \\
\text { Investment } \\
\text { (ten thousand } \\
\text { yuan) }\end{array}$ & $\begin{array}{c}(3) \\
\text { Technological } \\
\text { investment } \\
\text { (ten thousand } \\
\text { yuan) }\end{array}$ & $\begin{array}{l}\text { (4) } \\
\text { Marketing } \\
\text { investment } \\
\text { (ten } \\
\text { thousand } \\
\text { yuan) }\end{array}$ & $\begin{array}{c}(5) \\
\text { Information } \\
\text { technology } \\
\text { (ten } \\
\text { thousand } \\
\text { yuan) }\end{array}$ & $\begin{array}{l}\text { (1) Total } \\
\text { profit (ten } \\
\text { thousand } \\
\text { yuan) }\end{array}$ & $\begin{array}{c}(2) \\
\text { Electricity } \\
\text { sales } \\
\text { (million } \\
\text { kwh) }\end{array}$ & $\begin{array}{c}\text { (3) Purchase } \\
\text { price } \\
\text { difference } \\
\text { (Y/ } \\
\text { thousand } \\
\text { kwh) }\end{array}$ \\
\hline 1 & Fujian & 1260422 & 1158031 & 69000 & 153615 & 17139 & 239868 & 1397.80 & 214.16 \\
\hline 2 & Tianjin & 620911 & 547966 & 22845 & 111471 & 12491 & 95404 & 6078.01 & 237.29 \\
\hline 3 & Hebei & 912164 & 850828 & 40977 & 118861 & 13541 & 89700 & 13908.74 & 210.08 \\
\hline 4 & Jiangsu & 2977447 & 2765963 & 121570 & 388372 & 17518 & 686197 & 38488.39 & 152.91 \\
\hline 5 & Shandong & 2804030 & 2615571 & 107399 & 283868 & 18150 & 595476 & 32978.29 & 123.09 \\
\hline 6 & Shanghai & 1079683 & 628907 & 128095 & 153731 & 29877 & 110202 & 11174.96 & 224.62 \\
\hline 7 & Shanxi & 926989 & 807855 & 46466 & 185648 & 13989 & 88613 & 16295.99 & 126.32 \\
\hline 8 & Zhejiang & 2290509 & 2134974 & 99994 & 239306 & 18355 & 588559 & 28026.15 & 217.98 \\
\hline 9 & Anhui & 1125446 & 961436 & 107345 & 126241 & 15914 & 75821 & 1250.51 & 191.20 \\
\hline 10 & Beijing & 643251 & 594054 & 28141 & 132705 & 14041 & 152093 & 7920.60 & 206.48 \\
\hline 11 & Hubei & 1136556 & 1008999 & 53240 & 171112 & 17442 & 71546 & 1190.21 & 196.62 \\
\hline 12 & Hunan & 891914 & 776652 & 45236 & 155489 & 16123 & 71723 & 961.89 & 200.39 \\
\hline 13 & Henan & 1387564 & 1258219 & 87000 & 122140 & 18701 & 126149 & 2399.22 & 112.26 \\
\hline 14 & Jiangxi & 877297 & 800046 & 22470 & 102954 & 16176 & 65327 & 730.40 & 252.21 \\
\hline 15 & Sichuan & 2838232 & 2592478 & 157049 & 181748 & 19244 & 99523 & 180.40 & 159.64 \\
\hline
\end{tabular}

Data source: Transportation Monitoring Center of State Grid Corporation of China.

$R_{u}^{2}$ and $R_{s}^{2}$ are values of goodness of fit for unrestraint or restraint.

(3) In the given significance level $\alpha$, the threshold of statistics is obtained: $F_{\alpha}(m, n-k-1)$.

(4) Do the hypothesis test: if $|F| \geq F_{\alpha}(m, n-k-1)$, $H_{0}$ is refused and $H_{1}$ is accepted, which means no constraints for model parameters; conversely, $H_{0}$ is accepted.

\section{Example Simulation}

According to the evaluation index system of smart grid with high efficiency characteristic (to optimize asset utilization efficiency and power network operation efficiency) by EPRI, we can select appropriate economic indicators as input and output cells for evaluation model combined with development strategy of smart grid in China [18-20]. Table 1 takes 15 power companies as assessment objects and collects section data in the same period. All of the data come from Transportation Monitoring Center of State Grid Corporation of China. Figure 2 shows input quantity distribution of each company.

Some data is taken as the reference data set, including inputs 1, 2, 3, 4, and 5 and output of 1,2, and 3; then, following regression results will be got though software package SPSS Statistics. The regression equation could be explained: $\delta_{i t}$ is error term of power company $i$ in $t$ period. The result of goodness of fit is close to 1 . Additionally, considering Std. and $t$-test statistic, it shows fitting model coefficient saliency

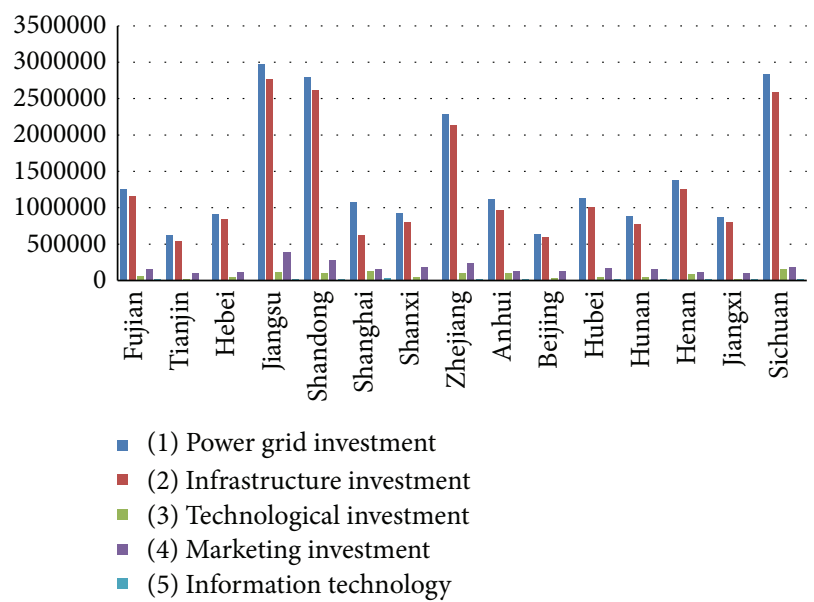

FIGURE 2: Input quantity distributions for power company.

is good. What is more, the sum of elasticity coefficient is estimated to be more than 1 , so it can be seen that the current smart grid construction belongs to type of increasing returns to scale. If capital investment and enterprise labor number become $n$ times, the output will be greater than $n$ times. This can also be verified by hypothesis testing of the following constraints:

$$
\begin{aligned}
\ln y_{i t} & =\left(\delta_{i t}-0.17\right)+1.523+0.74 \ln k_{i t}+0.341 \ln l_{i t} \\
\text { Std. } & =(0.714)(0.196)
\end{aligned}
$$


TABLE 2: The results of technical efficiency and allocative efficiency.

\begin{tabular}{lcccc}
\hline Order & Technical inefficiency & Technical efficiency & Technical efficiency & Allocative efficiency \\
& $u_{i}$ & $($ SFM $)$ & 0.616 & 0.564 \\
1 & 0.32 & 0.729 & 0.752 & 0.743 \\
3 & 0.17 & 0.846 & 0.615 & 0.545 \\
4 & 0.33 & 0.718 & 0.799 & 0.782 \\
5 & 0.14 & 0.869 & 0.733 & 0.733 \\
6 & 0.17 & 0.841 & 0.988 & 0.861 \\
7 & 0.09 & 0.916 & 0.455 & 0.248 \\
8 & 0.76 & 0.466 & 1 & 0.911 \\
9 & 0.06 & 0.944 & 0.765 & 0.752 \\
10 & 0.16 & 0.851 & 1 & 0.881 \\
11 & 0.07 & 0.929 & 0.403 & 0.208 \\
12 & 0.86 & 0.422 & 0.431 & 0.218 \\
13 & 0.82 & 0.439 & 0.923 & 0.782 \\
15 & 0.14 & 0.872 & 0.647 & 0.614 \\
\end{tabular}

$$
t=(2.309)(4.279) \quad(1.679)
$$

$$
\left(R^{2}\right)_{t}=0.891
$$

If $\alpha_{i t}+\beta_{i t}=1$, the fitting regression equation and the corresponding goodness of fit can be obtained:

$$
\begin{aligned}
\ln \left(\frac{y_{i t}}{l_{i t}}\right) & =2.403+0.878 \ln \left(\frac{k_{i t}}{l_{i t}}\right) \\
\left(R_{s}^{2}\right)_{t} & =0.692 .
\end{aligned}
$$

$F$ value is 38.62 by calculating. When given a significant level $\alpha$ of $0.05, F_{0.05}(1,12)=4.75$. Because of $F>F_{0.05}(1,12), H_{0}$ is refused.

4.1. Basic Situation Analysis. Through regression analysis and the test of parameter and model, the efficiency assessment function of smart grid based on Stochastic Frontier Model is obtained. Substituting reference data into this model can obtain technical efficiency and allocative efficiency index values of each company, as shown in Table 2 and in Figure 3.

Results are obtained by SFM method in Table 2 and in Figure 3. From the result, it is obvious that technical efficiency for companies 6,8 , and 10 is high and for companies 7 , 11, and 12 is low. Through the DEA method, there are the same results. Therefore, comparing the results through the method in this paper with DEA method can obtain the same results. But the approach of data processing is different, so the resulting data value of technology efficiency is different. In addition, efficiency evaluation value of DEA usually has 100\% valid conclusions, such as companies 8 and 10. Because the Stochastic Frontier Model has considered nonefficiency item in management and error term, it has no extreme evaluation

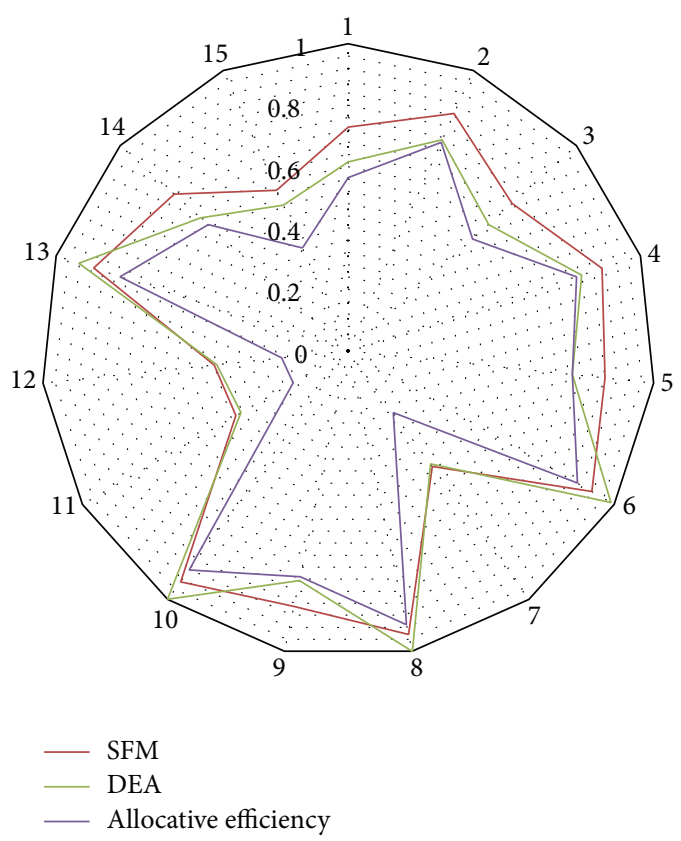

FIGURE 3: Technical efficiency comparison.

value. When technical efficiency in one company is close to another, this method can reflect the difference, but DEA method often draws the conclusion that two things are equal.

Calculation results of the allocative efficiency show that power companies 6,8 , and 10 have higher technical efficiency, and companies 7, 11, and 12 are lower. The result shows that the distribution law is similar to the technical efficiency, and high technical efficiency can also lead to high allocative efficiency. However, index value among power companies has big difference. For example, the eighth power company has 
TABLE 3: New variable data collection.

\begin{tabular}{lcccc}
\hline Order & Power company & $\begin{array}{c}\text { (6) Total installed capacity } \\
\left(10^{4} \mathrm{Kw}\right)\end{array}$ & $\begin{array}{c}\text { (7) Electricity } \\
\left(10^{8} \mathrm{Kwh}\right)\end{array}$ & $\begin{array}{c}\text { (8) } \\
\text { Unit power distribution cost } \\
\left(\text { yuan } / 10^{3} \text { Kwh }\right)\end{array}$ \\
\hline 1 & Fujian & 3885.4 & 1579.5 & 128.59 \\
2 & Tianjin & 1132.1 & 711.9 & 163.48 \\
3 & Hebei & 2618.2 & 1621.0 & 160.13 \\
4 & Jiangsu & 7531.9 & 4580.9 & 117.41 \\
5 & Shandong & 7079.8 & 3794.7 & 131.40 \\
6 & Shanghai & 2143.3 & 1353.5 & 180.34 \\
7 & Shanxi & 5454.9 & 1765.8 & 98.18 \\
8 & Zhejiang & 6170.3 & 3213.4 & 169.96 \\
9 & Anhui & 3532.1 & 1361.1 & 161.35 \\
10 & Beijing & 765.6 & 874.3 & 163.21 \\
11 & Hubei & 5787.6 & 1507.8 & 204.64 \\
12 & Hunan & 3311.6 & 1346.5 & 198.45 \\
15 & Henan & 5764.7 & 2747.7 & 102.00 \\
\hline
\end{tabular}

Data source: Transportation Monitoring Center of State Grid Corporation of China.

a strong resource optimization allocation in the smart grid construction, while companies 7, 11, are 12 are weak.

As a whole, these companies have high technical efficiency and low allocative efficiency (means are 0.745 and 0.618). This shows that the smart grid can get higher yield with advanced technology in particular year, but it is still in the lower level in optimization allocation of resources.

4.2. Multiple Scenarios Analysis. Sensitivity analysis on efficiency evaluation model was conducted. Data includes input variable 6-Total installed capacity $(104 \mathrm{Kw})$; input variable 7Electricity (108 Kwh); input variable 8-Unit power distribution cost (yuan/103 Kwh). The following scene is assumed: Scene 1 is a set of basic data; Scene 2 is a set of basic data and new input variable 6; Scene 3 is a set of basic data and all new input variables; Scene 4 is a set of basic data and new input variables 7 and 8 . New variable data collection is shown in Table 3 , and the contrast of new investment for each company is expressed in Figure 4.

According to the stochastic frontier analysis model, results of technical and allocative efficiency with different scenarios are shown in Tables 4 and 5 and Figures 5 and 6.

In order to compare the allocation efficiency of different provinces under different situations, the allocation efficiency of four scenarios is sorted, and results are shown in Table 6.

From the results of technical efficiency and allocative efficiency, we can see that the efficiency is approved through new input variable. The results show that the advanced technology and management mechanism make the full use of technology and capital, and the efficiency level of power companies is effectively improved.

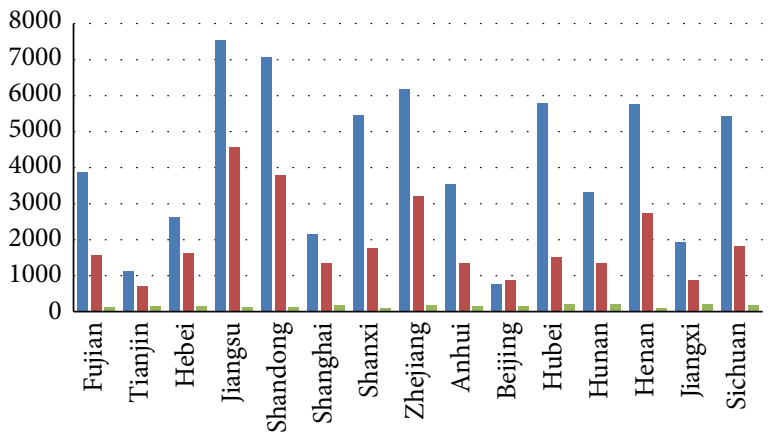

(6) Total installed capacity

(7) Electricity

(8) Unit power distribution cost

FIGURE 4: Contrast of new investment for each company.

From Table 6, it shows that allocative efficiency in Zhejiang, Beijing, and Shanghai is the best. Considering new input variables, allocative efficiency of the three regions is still ranked in the top three. Secondly, without thinking of new variables, the allocative efficiency of Jiangxi is superior to the Hebei, but thinking of any new variables, allocative efficiency of Hebei is superior to the Jiangxi, which suggests that Hebei has better implementation effect than Jiangxi in transmission and distribution costs.

\section{Conclusion}

This paper has proposed a new method for evaluating technical and allocative efficiency of smart grid based on 
TABLE 4: The results of technical efficiency in different situation.

\begin{tabular}{lcccc}
\hline \multirow{2}{*}{ Order } & \multicolumn{4}{c}{ Technical efficiency } \\
& Scenario 1 & Scenario 2 & Scenario 3 & Scenario 4 \\
\hline 1 & 0.72864 & 0.75 & 0.816 & 0.837 \\
2 & 0.84645 & 0.89 & 0.93 & 0.963 \\
3 & 0.71775 & 0.74 & 0.803 & 0.855 \\
4 & 0.86922 & 0.87 & 0.923 & 0.944 \\
5 & 0.84051 & 0.88 & 0.941 & 0.967 \\
6 & 0.91575 & 0.92 & 0.95 & 0.971 \\
7 & 0.46629 & 0.61 & 0.63 & 0.651 \\
8 & 0.94446 & 0.95 & 0.97 & 0.991 \\
9 & 0.8514 & 0.88 & 0.953 & 0.973 \\
10 & 0.92862 & 0.92 & 0.935 & 0.956 \\
11 & 0.42174 & 0.51 & 0.554 & 0.575 \\
12 & 0.43857 & 0.52 & 0.564 & 0.585 \\
13 & 0.87219 & 0.85 & 0.912 & 0.933 \\
14 & 0.76329 & 0.73 & 0.854 & 0.921 \\
15 & 0.57321 & 0.62 & 0.641 & 0.73 \\
\hline
\end{tabular}

TABLE 5: Results of allocative efficiency in different situation.

\begin{tabular}{lcccc}
\hline \multirow{2}{*}{ Order } & \multicolumn{4}{c}{ Allocative efficiency } \\
& Scenario 1 & Scenario 2 & Scenario 3 & Scenario 4 \\
\hline 1 & 0.5643 & 0.612 & 0.6487 & 0.701 \\
2 & 0.7425 & 0.751 & 0.7961 & 0.821 \\
3 & 0.5445 & 0.634 & 0.6720 & 0.731 \\
4 & 0.7821 & 0.732 & 0.7759 & 0.838 \\
5 & 0.7326 & 0.711 & 0.7537 & 0.814 \\
6 & 0.8613 & 0.921 & 0.9531 & 0.966 \\
7 & 0.2475 & 0.432 & 0.4579 & 0.632 \\
8 & 0.9108 & 0.912 & 0.9550 & 0.977 \\
9 & 0.7524 & 0.773 & 0.8194 & 0.885 \\
10 & 0.8811 & 0.911 & 0.9234 & 0.934 \\
11 & 0.2079 & 0.326 & 0.3456 & 0.543 \\
12 & 0.2178 & 0.543 & 0.5756 & 0.632 \\
13 & 0.7821 & 0.811 & 0.8597 & 0.928 \\
14 & 0.6138 & 0.601 & 0.6371 & 0.688 \\
15 & 0.3663 & 0.442 & 0.4685 & 0.654 \\
\hline
\end{tabular}

Stochastic Frontier Model and Data Envelopment Analysis. In the establishment of efficiency assessment model, it can reflect the technology production capacity and optimal allocation ability for resources of smart grid. The following main conclusions are obtained by example simulation:

(1) By establishing the efficiency assessment model of smart grid based on the stochastic frontier function, the effect of input-output relationship on efficiency is analyzed under random factors.

(2) Technical efficiency reflects the ability to get the maximum return with fixed investment. The same numerical distribution law can be obtained with the method in this paper.

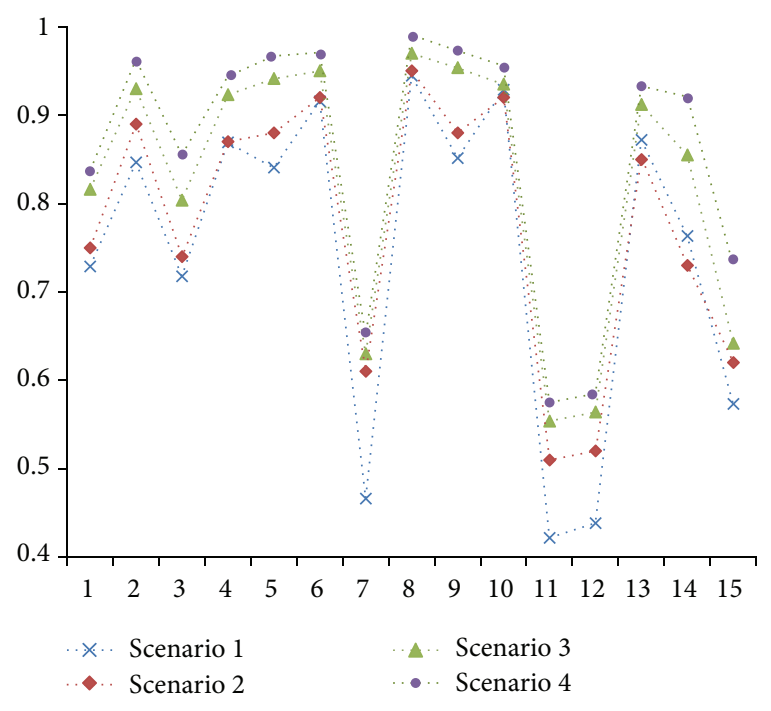

FIGURE 5: Comparison of results of technical efficiency in different situation.

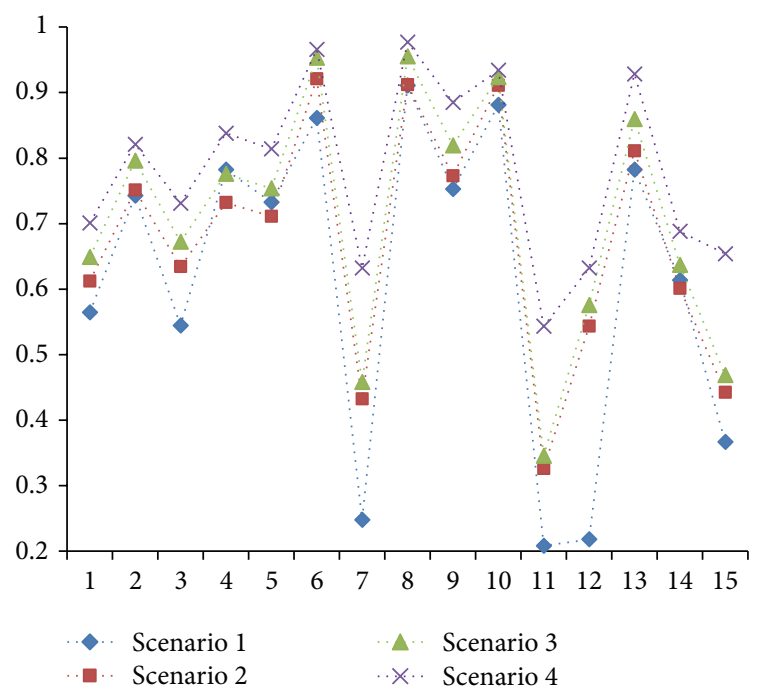

FIGURE 6: Comparison of results of allocative efficiency in different situation.

(3) Allocation efficiency reflects the overall capability of optimizing the allocation of resources. The proposed allocation efficiency model can avoid the requirement of the cost function for the price information and provide a reference for smart grid to evaluate resources optimization ability.

(4) Results were greatly different with different input variable, which shows the proposed allocation efficiency can be adjusted according to the actual need.

(5) Results of contrasting allocative efficiency in 15 regions showed that the efficiency of Zhejiang, Shanghai, and Beijing is much better than others, and it can have the same conclusion considering new variables. 
TABLE 6: Sort of allocative efficiency.

\begin{tabular}{|c|c|c|c|c|c|}
\hline \multirow{2}{*}{ Order } & \multirow{2}{*}{ Power company } & \multicolumn{4}{|c|}{ Sort } \\
\hline & & Scenario 1 & Scenario 2 & Scenario 3 & Scenario 4 \\
\hline 1 & Fujian & 2 & 3 & 3 & 3 \\
\hline 2 & Tianjin & 7 & 6 & 6 & 7 \\
\hline 3 & Hebei & 11 & 9 & 9 & 9 \\
\hline 4 & Jiangsu & 4 & 7 & 7 & 6 \\
\hline 5 & Shandong & 8 & 8 & 8 & 8 \\
\hline 6 & Shanghai & 3 & 1 & 2 & 2 \\
\hline 7 & Shanxi & 13 & 14 & 14 & 13 \\
\hline 8 & Zhejiang & 1 & 2 & 1 & 1 \\
\hline 9 & Anhui & 6 & 5 & 5 & 5 \\
\hline 10 & Beijing & 10 & 10 & 10 & 10 \\
\hline 11 & Hubei & 15 & 15 & 15 & 15 \\
\hline 12 & Hunan & 14 & 12 & 12 & 14 \\
\hline 13 & Henan & 5 & 4 & 4 & 4 \\
\hline 14 & Jiangxi & 9 & 11 & 11 & 11 \\
\hline 15 & Sichuan & 12 & 13 & 13 & 12 \\
\hline
\end{tabular}

\section{Conflict of Interests}

The authors declare that there is no conflict of interests regarding the publication of this paper.

\section{References}

[1] C. Anwei, Research on the technical economic problems of the smart gri [Ph.D. thesis], Chongqing University, 2012.

[2] B. Yanbing, Research on Key Technologies of Communication Middleware for Smart Grid, Shandong University, Jinan, China, 2013.

[3] S. Cai, S. Wang, C. Wang, and G. Jia, "Economic perspective of smart grid," Automation of Electric Power Systems, vol. 20, pp. 13-87, 2009.

[4] Y. Xiaobao and T. Zhongfu, "Differentiated evaluation of smart grid in the improved hall three-dimensional perspective," Modern Electric Power, vol. 32, no. 4, pp. 42-48, 2015.

[5] Z. Yan, L. Li, D. Han, H. Chen, and N. Yu, "Evaluation model for low-carbon electricity production efficiency based on improved super efficiency data envelopment analysis method," Automation of Electric Power Systems, vol. 38, no. 17, pp. 170-176, 2014.

[6] D. K. Jha and R. Shrestha, "Measuring efficiency of hydropower plants in Nepal using data envelopment analysis," IEEE Transactions on Power Systems, vol. 21, no. 4, pp. 1502-1511, 2006.

[7] Price Cap Regulation in the Electricity Sector, Netherland Electricity Regulatory Service, Hague, The Netherlands, 1999.

[8] Z. Hao, Research on resources optimal allocation in distribution network [Ph.D. thesis], North China Electric Power University, Beijing, China, 2013.

[9] W. Ning and L. Dongxiao, "Research on evaluation to resource allocation efficiency of power grid enterprise based on SE-DEA model," Power Demand Side Management, vol. 3, pp. 23-26, 33, 2009.

[10] X. Ma, Y. Wu, H. Fang, Y. Sun, Y. Wu, and Y. Shen, "Microgrid configuration based on reliability assessment," Automation of Electric Power Systems, vol. 9, pp. 73-99, 2011.
[11] D. Zhang, Research on the optimization allocation and the operation of micro-grid [M.S. thesis], Donghua University, 2013.

[12] A. Kumar, R. Shankar, and R. M. Debnath, "Analyzing customer preference and measuring relative efficiency in telecom sector: a hybrid fuzzy AHP/DEA study," Telematics and Informatics, vol. 32, no. 3, pp. 447-462, 2015.

[13] Z. Zhang and Z. Yu, "Analysis of production efficiency in railway industry based on the stochastic frontier function," Journal of East China Jiaotong University, vol. 4, pp. 108-112, 2012.

[14] S.-S. Lee, S.-H. Ahn, J.-H. Park et al., "South Korean power distribution system-based operation, market structure and regulation strategies under distributed generation and smart grid," in Proceedings of the IEEE Power and Energy Society General Meeting (PES '12), pp. 1-7, IEEE, San Diego, Calif, USA, July 2012.

[15] D. Han, Z. Yan, and Y. Liu, "An evaluation method for the development of intelligent techniques based on Cobb-Douglas production function," Proceedings of the Chinese Society of Electrical Engineering, vol. 32, no. 1, pp. 71-77, 2012.

[16] Y. Liu and G. Gao, "Least square identification algorithm of capacitive current in power grid," Power System Protection and Control, vol. 8, pp. 49-58, 2010.

[17] L. Yanfang, W. Dong, and C. Shuwen, "The threshold effect of import and export trade on the productivity, income and environment $-\mathrm{a}$ nonlinear panel model based on provincial GDP during 1992-2010," China Economic Quarterly, vol. 2, pp. 703-730, 2015.

[18] W. Wang, "Energy saving mode of smart grid," Public Communication of Science \& Technology, vol. 16, pp. 76-77, 2012.

[19] X. Hu, "Smart grid-a development trend of future power grid," Power System Technology, vol. 14, pp. 1-5, 2009.

[20] C. Liu and Y. Wang, "Discussion on the construction of efficient communication network of smart grid based on cloud technology," Electric Power Information Technology, vol. 7, pp. $18-21,2010$. 


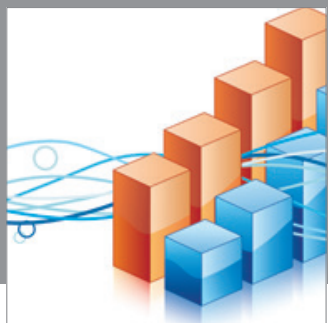

Advances in

Operations Research

mansans

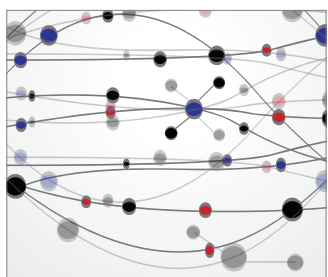

The Scientific World Journal
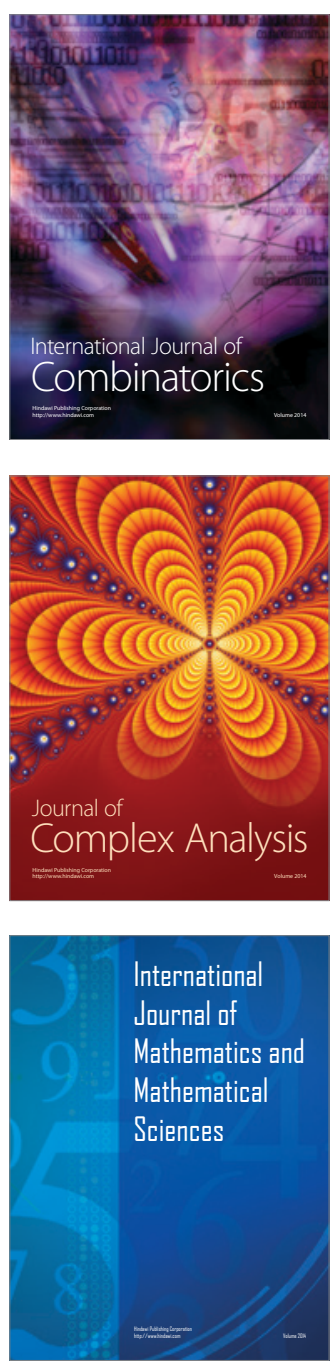
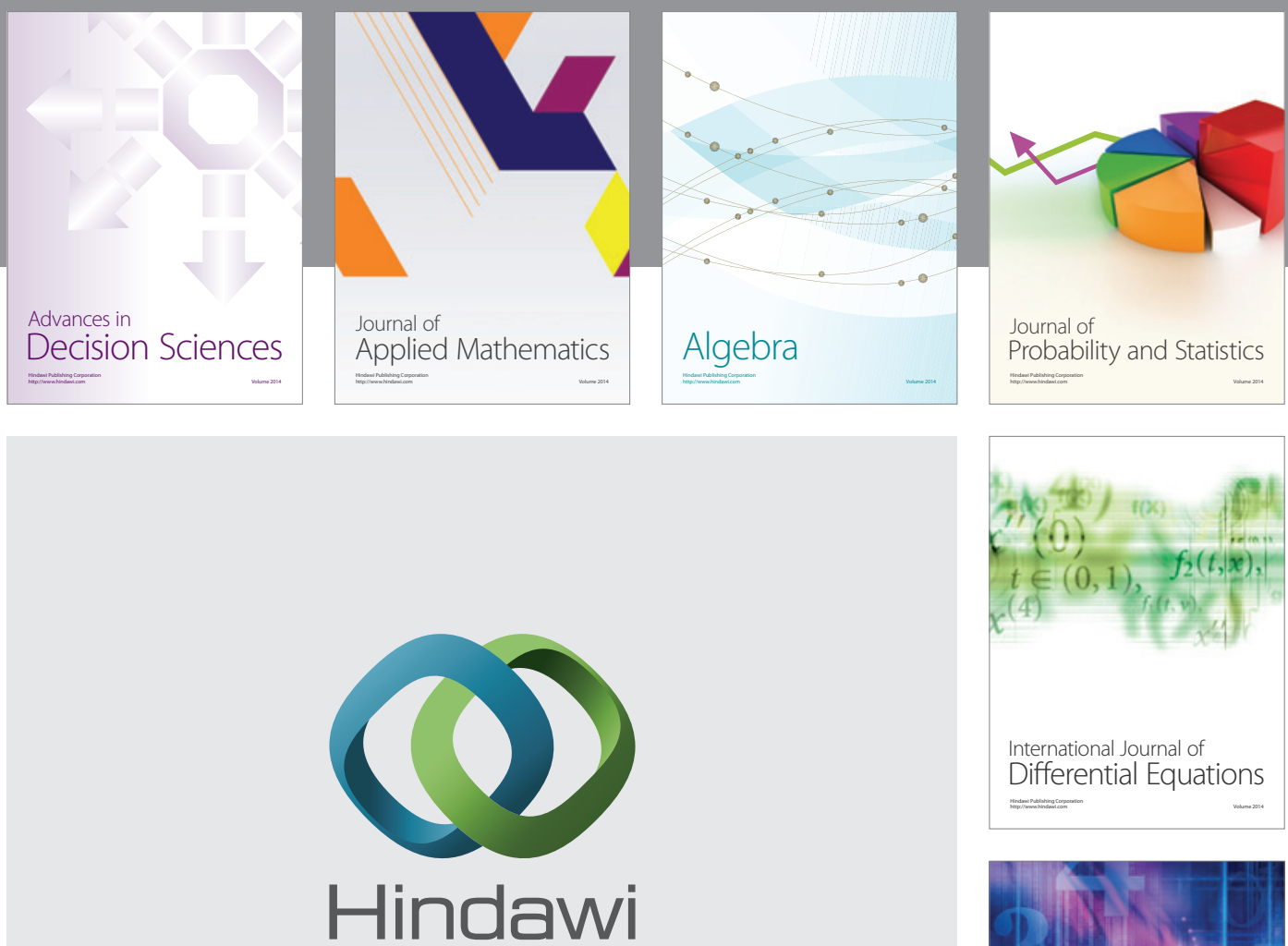

Submit your manuscripts at http://www.hindawi.com
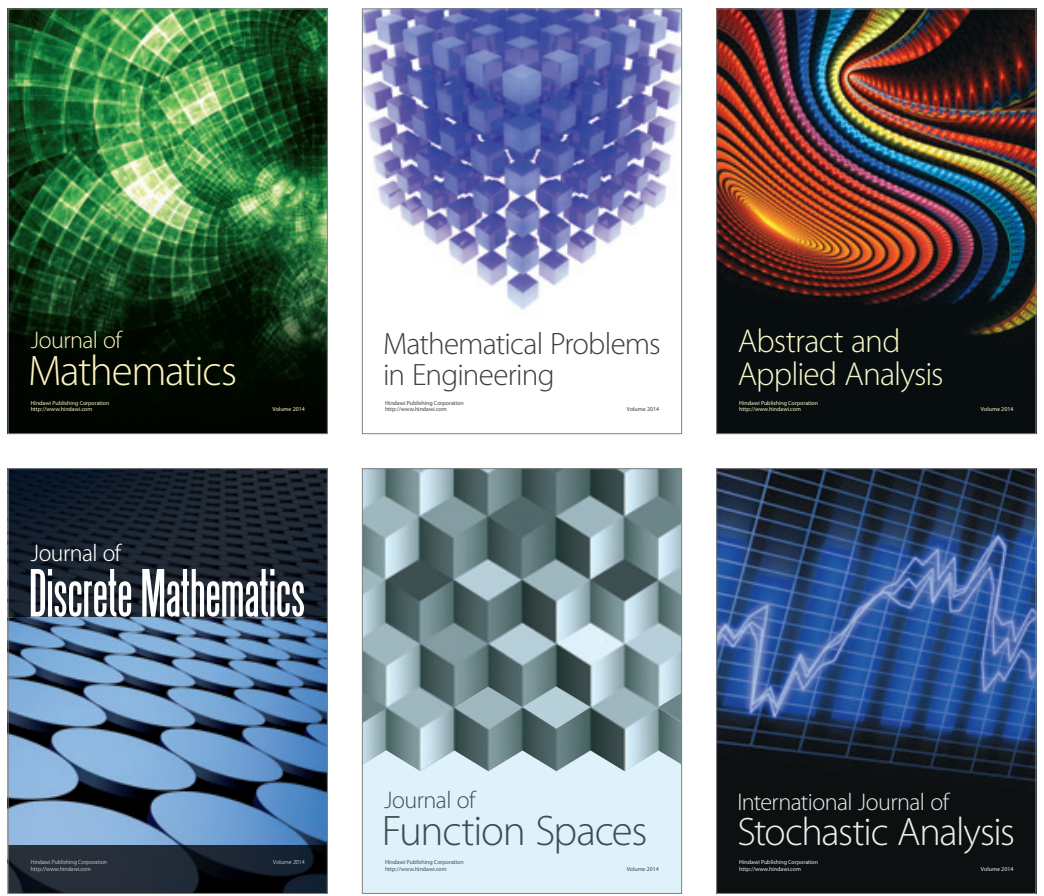

Journal of

Function Spaces

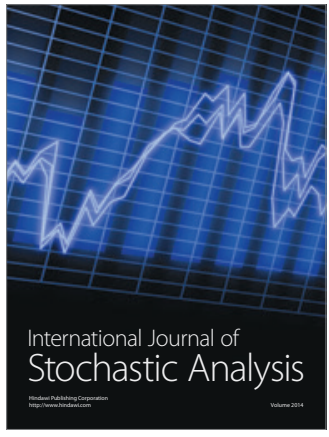

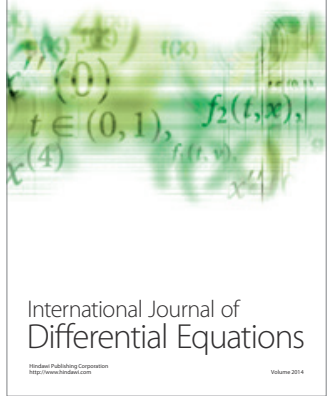
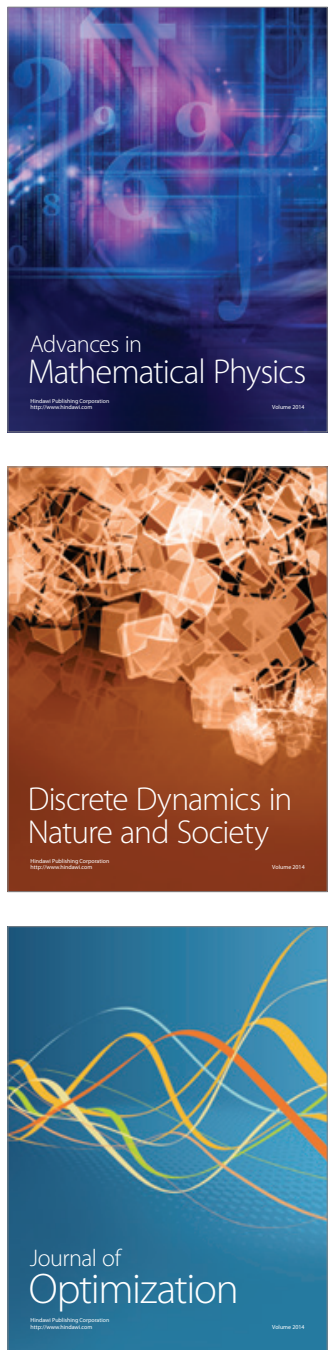